\title{
Journal of Materials Research Seeks Manuscripts for Upcoming Issues
}

Inaugural Issue Published, Distributed Worldwide

The first issue of lournal of Materials Researh, the official journal of the Materials Research Society, has recently been published and mailed to members of the Society and IMR subscribers throughout the world. This landmark issue contains 23 research papers, plus rapid communications and an extensive review article (see topics listed in the January/February 1986 issue of MRS BULLETIN). Some of the topics included are quasicrystals, rapid solidification, and transmission electron microscopy. Editor in Chief Charles B. Duke praised the 19 principal editors and many reviewers whose dedication and hard work has resulted in a very exciting first issue.

The inaugural issue incorporates JMR's unique "Contents by Topic," which Duke explained is to enable readers to readily locate articles of interest to them. The issue also contains complete information for contributors, guidelines for author-developed index terms, and a facsimile of a copyright transfer form, for use by researchers intending to submit manuscripts for consideration for future issues.

The second issue is now under preparation, and Duke reports that the response of the materials research community continues at a high level, ensuring that future issues of JMR will present some of the most significant developments in materials research today.

Manuscripts are being sought for upcoming issues of JMR, and should be sent to Charles B. Duke, Editor in Chief, Journal of Materials Research, Xerox Webster Research Center, 800 Phillips Road, 0114/38D, Webster, NY 14580. See "Information for Contributors" reproduced in this issue of the BULLETIN

\section{Special Air Shipment Available}

\section{Journal of Materials Research}

The first issue of Journal of Materials Research has just been published, spanning recent developments contributing to the advancement of materials. As a special service to MRS members in Europe and Asia, this inaugural issue has been shipped by air freight to ensure prompt delivery. All subsequent issues to MRS members in Europe and Asia will be shipped by surface rate, unless you opt to receive the journal by air at one of the applicable rates listed below. To receive your subscription to JMR by air freight, send your request with payment to Materials Research Society, 9800 McKnight Road, Suite 327, Pittsburgh, PA 15237. (Nonmember subscribers should send orders for air freight to American Institute of Physics, 335 East 45th Street, New York, NY 10017).

Special JMR Air Freight Rates:

Air Freight-Europe $\$ 15.00$

Air Freight-Asia $\mathbf{2 3 . 0 0}$ 